\title{
Social group entry rules may limit population resilience to patchy habitat disturbance
}

\author{
Darren J. Coker ${ }^{1,2, *}$, Stefan P. W. Walker ${ }^{1}$, Philip L. Munday ${ }^{1,3}$, Morgan S. Pratchett ${ }^{1}$ \\ ${ }^{1}$ ARC Centre of Excellence for Coral Reef Studies, and ${ }^{3}$ School of Marine and Tropical \\ Biology James Cook University, Townsville, Queensland 4810, Australia \\ 22AIMS@JCU, Australian Institute of Marine Studies, James Cook University, Townsville, Queensland 4811, Australia
}

\begin{abstract}
Habitat degradation often results in resident displacement. One potentially important determinant of the lethality of such displacement is the nature of interactions between displaced individuals and the occupants of nearby, intact habitat. Here, we show that displaced individuals of the coral-dwelling fish Dascyllus aruanus have very low potential to join a new group due to targeted and cooperative aggression by conspecific resident group members. Residents were found to be relatively non-aggressive towards familiar displaced individuals seeking group re-entry but highly aggressive towards displaced unfamiliar prospective group members. The extent of individual resident aggression towards unfamiliar individuals correlated with groupbased dominance rank, resident-to-intruder size similarity, and social group size, such that higher ranking resident group members disproportionately contributed to intruder defence. Subsequent group re-entry by displaced familiar individuals was observed $100 \%$ of the time, compared to an $18 \%$ group entry success rate for displaced unfamiliar individuals. Results indicate that pre-existing social bonds and associated cooperative aggression can generate greater habitat-disturbance lethality for displaced inhabitants than that predicted by mobility potential and alternative habitat availability alone. This implies that social group entry rules may be an important determinant of population resilience to patchy habitat disturbance.
\end{abstract}

KEY WORDS: Aggression · Competition · Coral reef fish · Displacement · Familiarity · Group dynamics $\cdot$ Social bonds $\cdot$ Social discrimination

\section{INTRODUCTION}

Many animals are known to rely on specific habitat types for food, shelter, or breeding sites. Thus, degradation or loss of those key habitats during natural and anthropogenic disturbance often results in significant local loss of inhabitants, either via direct mortality or displacement (Groombridge 1992, Fahrig 1997, Jones et al. 2004). However, predicting the net numeric impact of such disturbances for inhabitants, and the resilience of associated populations and communities in general, remains difficult without knowledge of the fate of displaced individuals (Wilson et al. 2006).
One potentially important determinant of the fate of displaced individuals is the nature of interactions between displaced individuals and the occupants of nearby intact habitat. Group exclusion behaviour can be expected from residents whenever the net fitness gains of that behaviour outweigh the expected net benefits of group growth (Krause \& Ruxton 2002) and can lead to restricted group entry dynamics whenever resource holding potential (RHP) (Parker 1974, Maynard-Smith 1982) is weighted in favour of preexisting group members. In turn, socially prevented or delayed relocation success for displaced individuals can diminish individual fitness by increasing exposure to harsh physical environment(s) and pred- 
ators and by limiting food and mate availability (Holbrook \& Schmitt 2002, Krause \& Ruxton 2002, McCormick 2009).

The outcomes of patchy habitat disturbance for displaced individuals should thus be strongly tied to the sources of group benefits and costs. For example, if some residents have greater RHP and the cost-benefit ratio of grouping is simply density-dependent, then the group entry success rate for displaced individuals may be expected to decrease only as alternative habitat patches reach local carrying capacity. Alternatively, if some residents have greater RHP and the cost-benefit ratio of grouping is dependent on the characteristics of prospective group members (e.g. relatedness, sex, pair-wise body size, familiarity), then intruder group entry success rate may be expected to fall short of local carrying capacity, due to a reduction in available intruder-resident group phenotypic matching options. This, in turn implies that the net lethality of habitat displacement for adults can be greater than that predicted by mobility potential and alternative habitat availability alone.

Coral reefs support many group-forming fishes that are reliant on specific species or genera of live coral during their juvenile and/or adult life (Shpigel \& Fishelson 1986, Munday 2001, Jones et al. 2004, Wilson et al. 2006). Coral-dwelling fishes use live coral colonies for shelter and are often restricted to territorial areas or individual coral colonies (Forrester 1991, Wong et al. 2008). For these fishes, the continuous loss of live coral habitat as a result of natural and anthropogenic disturbances can cause significant net reductions in the abundance and diversity of many coraldwelling fishes (Munday 2004, Wilson et al. 2006, Pratchett et al. 2008). However, predicting the magnitude of these reductions is difficult without knowledge of how surviving inhabitants respond to habitat disturbance and loss. Degradation and mortality of corals can be patchy, with some corals impacted more than others (e.g. Marshall \& Baird 2000). Recent studies show that coral-dwelling fishes, such as the damselfish Dascyllus aruanus, will often vacate deceased coral colonies (Feary 2007, Bonin et al. 2009, Coker et al. 2012) and attempt to relocate to neighbouring healthy habitat (Coker et al. 2012). However, when provided with a choice, these displaced habitat seekers often preferentially select habitat-containing conspecifics, as opposed to vacant healthy habitats (Sweatman 1983, Ben-Tzvi et al. 2009, Coker et al. 2012). Thus, their success in circumventing fitness losses (or death) associated with habitat displacement via relocation will depend on their capacity to join established groups of conspecifics.
Here, using Dascyllus aruanus, we experimentally elucidate the rules governing group entry success for displaced adults. Specifically, we test the hypothesis that individual residents discriminate against individuals seeking group membership on the basis of pair-wise body size and pre-established social bonds (i.e. familiarity), independent of group size. Discrimination on the basis of pair-wise body size may be expected because relatively larger intruders represent a greater threat to social dominance and breeding rank (Forrester 1991, Wong et al. 2007). Discrimination on the basis of familiarity may be expected when the cost-benefit ratio of grouping is sensitive to repeated interactions between group members and the subsequent emergence of stable dominance relationships (Jaeger 1981, Frostman \& Sherman 2004, Griffiths et al. 2004, Jordan et al. 2010). It is thus predicted that familiar intruders and intruders that are either larger than the largest resident (due to dominance) or smaller than the smallest resident (due to resident tolerance) will have the greatest rates of group entry success.

\section{MATERIALS AND METHODS}

Dascyllus aruanus (family Pomacentridae) were collected from Lizard Island, Great Barrier Reef, Australia $\left(14^{\circ} 40^{\prime} \mathrm{S}, 145^{\circ} 28^{\prime} \mathrm{E}\right)$, and experiments were conducted at Lizard Island Research Station (LIRS). D. aruanus forms highly stable polygynous breeding societies within live coral colonies (Cole 2002, BenTzvi et al. 2009, Cant 2011). Together with their coral host Stylophora pistilata, 20 naturally occurring groups of $D$. aruanus (2 to 10 members) were located and collected from the wild. Fish were caught using clove oil solution and hand nets (Munday \& Wilson 1997); host colonies were detached from the reef once fish were removed and transported to LIRS with their resident fish for trials. Host colonies were then placed at one end of separate $1000 \mathrm{l}$ flow-through tanks $(2.2 \times 1.2 \times 0.5 \mathrm{~m})$ containing a thin layer of marine sand on the bottom. All fish were measured (total length [TL] in $\mathrm{mm}$ ), tagged subcutaneously with coloured elastomer (Northwest Marine Technologies) for visual individual recognition, and then placed back with their host colony. A separate batch of $D$. aruanus $(\mathrm{n}=66)$ were caught from reefs distant to the reefs of previously collected groups and transported to LIRS to function as unfamiliar intruders. Intruders were collected from the reef before experimental trials and housed together overnight in large aquaria containing coral structure. Resident fish 
ranged from 18 to $59 \mathrm{~mm}$ TL; intruding fish ranged from 16 to $59 \mathrm{~mm}$ TL. All established groups were acclimated for $2 \mathrm{~d}$ prior to experimental trials.

To examine the potential for social group entry by unfamiliar adults, an individual was randomly selected, measured, and placed on a dead coral colony at the opposite end of the tank from a randomly selected resident group and host colony. Dead colonies and live occupied colonies were $1.8 \mathrm{~m}$ apart. Once placed on the dead colony in the tank, all individual intruders attempted to relocate across to the resident group colony within a few minutes. Occurrence of aggressive interactions by resident individuals (based on their unique visual tag) towards the habitat seeker, and whether or not the habitat seeker was successful at joining the group, was observed and recorded continuously over a $1 \mathrm{~h}$ period. A successful entry was defined as the intruder entering and remaining within the new colony and social group. Unsuccessful individuals would either not be able to gain entry or gain entry but be evicted immediately by resident members. Aggressive attacks were identified as chasing and biting (Katzir 1981). Residents were also observed to carry out 'frontal displays' (Katzir 1981) and 'jumps' (vertical movements; Katzir 1981); however, these dominance signals were not included in analyses as it was not always possible to distinguish the signal target (i.e. other residents or intruder). At the end of the trial, the intruder was removed from the tank and the study. This process was repeated for 66 habitat seekers among 12 resident groups ( 4 to 6 intrudes per resident group). Each resident group was left undisturbed (other than during feeding) for at least $24 \mathrm{~h}$ between each trial.

To examine whether group entry success differed as a function of intruder-resident familiarity, an additional 8 naturally occurring Stylophora pistilata coral colonies with associated Dascyllus aruanus (3 to 5 members) were collected from the reef and placed in large flow-through tanks (as above). After $5 \mathrm{~d}$ of acclimation, a group member was randomly selected, removed, and held in a separate tank. The individual was re-entered after $1 \mathrm{~h}$ onto a small piece of coral rubble at the other end of their original tank. For each introduction, aggression and group entry success or failure was monitored and recorded for $1 \mathrm{~h}$ (as above). If no aggression was recorded after $1 \mathrm{~h}$, the intruder was removed and the introduction repeated following removal for 7, 24 and $48 \mathrm{~h}$. If at any stage the resident members showed aggression towards the intruder when introduced, the trial was terminated and the time noted. This was repeated for each group member in each of the 8 social groups totalling 26 intruders. The purpose of this experiment was to examine whether resident members will show aggression to all intruding fish, even if they were previously members. The increasing length of removal was used to identify if the time that they were away from group members would influence their entry success.

A generalized additive model (GAM; MGCV package in R) (Hastie \& Tibshirani 1987) was used to explore relationships between the dependent variable $\ln$ (no. of attacks +1 ) (individual resident-tointruder aggression), the parametric predictor variables group size and group ID, and predictor non-parametric smoothing $(s)$ functions $s$ (residentgroup dominance rank) (determined by relative size within group), $s$ [n(resident size)- $\ln$ (intruder size)] (resident-intruder size similarity), and $s[\ln ($ intruder size)]. In this model, the significance of parametric terms is estimated from the $t$-distribution while the significance of non-parametric smoothing functions is estimated from the $F$-distribution.

Logistic regression, implemented in $\mathrm{R}$ as a general linear model with a binomial error distribution, was then used to explore relationships between the dependent variable group entry success and the predictor variables group size, $\ln ($ intruder size), and [ln(resident size)-ln(intruder size)] (size similarity between intruder and next largest resident individual). Predictors of group entry success for familiar habitat seekers were not explored due to a lack of variance in group entry success (i.e. 100\% success rate).

\section{RESULTS AND DISCUSSION}

All individuals on dead coral colonies tried to relocate to healthy coral colonies occupied by conspecifics within minutes of being introduced. Aggression from residents towards familiar displaced habitat seekers was found to be limited to dominance signals (i.e. frontal displays and jumps) with no physical attacks being recorded during group re-entry trials following any of the removal times. In contrast, resident aggression towards unfamiliar habitat seekers was found to be highly physical, consisting of frequent bites and chases (Fig. 1a,b). Total group physical aggression towards unfamiliar individuals was relatively consistent across group sizes, but peaked at intermediate group sizes (Fig. 1a). Mean individual resident aggression towards unfamiliar individuals declined significantly as a function of group size 

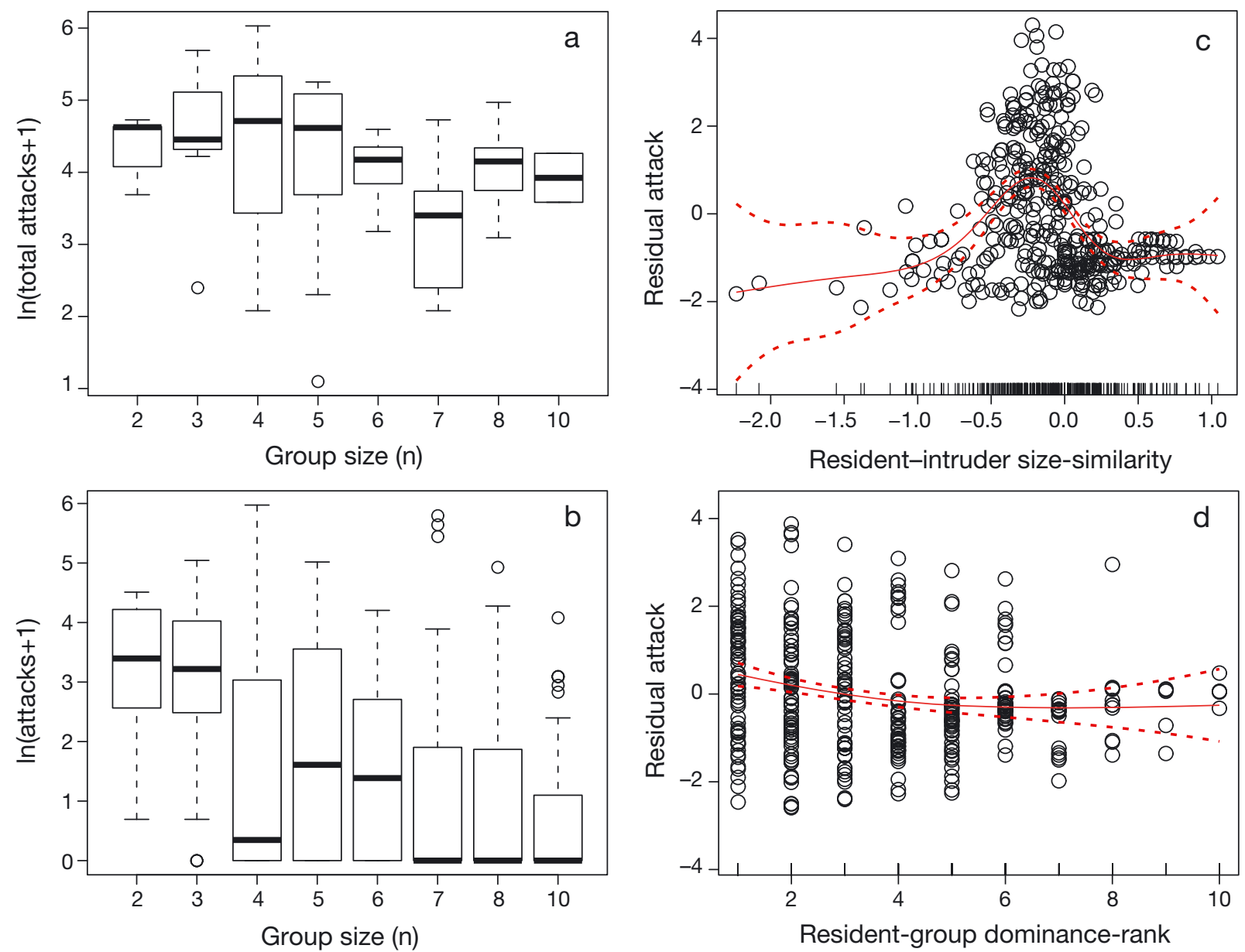

Fig. 1. Dascyllus aruanus. (a) Total resident group aggression, $\ln ($ total attacks +1$)$ and $(b-d)$ individual resident aggression, $\ln ($ attacks +1$)$, towards unfamiliar intruders as a function of $(a, b)$ resident group size, and the non-parametric smoothing functions (c) $s$ [ln(resident size) - $\ln ($ intruder size)] (resident-intruder size similarity) and (d) $s$ (resident dominance rank). Residuals in (c) and (d) were obtained from the reduced whole general additive model (see 'Materials and methods') ( $a$, b) Black horizontal lines: median; box: 25 and $75 \%$ quartiles; whiskers: 5 and $95 \%$ quantiles; O: outliers (>1.5 times interquartile range). (c,d) Solid red line: mean; dashed red line: $95 \%$ CI. Rug plot: sampling intensity of $x$-axis values. TL: total length in mm

(GAM; group size: $t=4.06, \mathrm{p}<0.01$; Fig. $1 \mathrm{~b}$ ), and significantly increased as a function of residentintruder size similarity $\left(\mathrm{GAM}_{;} s\right.$ (size similarity): $F_{6.3}=$ 12.77, p < 0.01; Fig. 1c) and resident group dominance rank (GAM; $s$ (rank): $F_{2.03}=4.8, \mathrm{p}<0.01$; Fig. 1d). Group ID had a non-significant effect on resident aggression (GAM; group ID: $t=0.34, \mathrm{p}=0.75)$. These results indicate the presence of a competitive aggression escalation response to both the severity of the threat to dominance (i.e. intruder-resident size similarity), and the value of the resource (dominance rank and hierarchy status for breeding), with the byproduct effect of reduced intruder defence costs for relatively smaller resident group members with an increase in group size.

Consistent with patterns of aggression, all familiar habitat seekers $(n=26)$ achieved group re-entry over a $48 \mathrm{~h}$ time period, while only $18 \%$ (12 of 66 ) of unfamiliar habitat seekers were successful in joining a group. Absolute body size was found to be the only significant predictor of group entry success for unfamiliar habitat seekers (logistic regression; body size: $Z=2.46, \mathrm{p}=0.014$ ), with smaller fish having a higher rate of success compared to larger fish (Fig. 2). Resident group size and size similarity between intruder and next largest resident (NLR) had no significant effect on group entry success of unfamiliar individuals (logistic regression; size similarity NLR: $Z=0.44$, $\mathrm{p}=0.66$; group size: $Z=0.17, \mathrm{p}=0.86$ ). These results indicate a strong combined prior occupancy weighting on RHP, a higher tolerance for increased group size with pair-wise familiarity, and indicates that group entry is controlled by the largest resident group members, resulting in an overall low group 


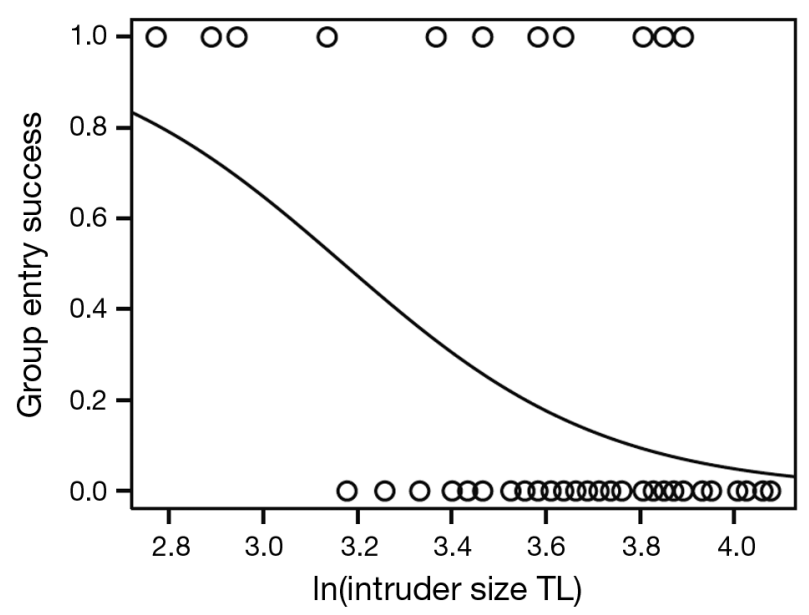

Fig. 2. Dascyllus aruanus. Logistic regression: group entry success for unfamiliar intruders as a function of intruder size. TL: total length in $\mathrm{mm}$

entry success rate for new habitat seekers over most of the adult body size distribution. These results are consistent with those of a recent related study on Dascyllus aruanus social groups in the wild, which showed familiarity and pair-wise body size to be the primary determinants of grouping tolerance among individuals in pre-established groups (Jordan et al. 2010). While aquaria experiments proved a suitable environment for collecting behavioural data, it must be acknowledge that relocating fish on the reef would potentially expose them to predators that may reduce their persistence and survivorship.

For many coral-dwelling fishes, the benefits of group living often far outweigh the benefits of solitary life over a range of group sizes and densities (Sweatman 1983, Mitchell 2005, Wong et al. 2007). While Dascyllus aruanus individuals prefer to associate with coral colonies containing conspecifics, and have the potential to relocate following habitat displacement (Coker et al. 2012), the present study demonstrates a major constraint to group entry for displaced individual adults following initial habitat disturbance. This constraint likely results in a number of negative fitness outcomes - such as increased predation risk, and decreases in foraging efficiency and opportunities for reproduction (Holbrook \& Schmitt 2002, Krause \& Ruxton 2002, McCormick 2009). This implies that social group entry rules can generate greater habitat-disturbance lethality for displaced inhabitants than that predicted by mobility potential and availability of alternative habitat alone. Importantly, prior occupancy effects on RHP, in addition to a range of discriminatory grouping behaviours (e.g. familiarity, relatedness, size, sex, condition, be- haviour) are likely to be common features in many social animals (Avise \& Shapiro 1986, Krebs \& Davis 1997, Dugatkin \& Reeve 2000, Wong et al. 2007, Walker \& McCormick 2009, Walker et al. 2010). Thus, for a range of taxa, social group entry rules may be an important determinant of population and community resilience to patchy habitat disturbance. This is particularly important given the predicted increase in coral habitat loss in the future.

Acknowledgements. We thank J. Nowicki, M. Trapon, and $\mathrm{K}$. Vlahakis for their assistance in the field, and the staff of Lizard Island Research Station for logistical support. Research was funded by AIMS@JCU and LIRS Ian Potter Doctorial Fellowship awarded to D.J.C.

\section{LITERATURE CITED}

Avise JC, Shapiro DY (1986) Evaluating kinship of newly settled juveniles within social groups of the coral reef fish Anthias squamipinnis. Evolution 40:1051-1059

Ben-Tzvi O, Kiflawi M, Polak O, Abelson A (2009) The effect of adult aggression on habitat selection by settlers of two coral-dwelling damselfishes. PLoS ONE 4:e5511

Bonin MC, Munday PL, McCormick MI, Srinivasan M, Jones GP (2009) Coral-dwelling fishes resistant to bleaching but not to mortality of host corals. Mar Ecol Prog Ser 394:215-222

> Cant MA (2011) The role of threats in animal cooperation. Proc Biol Sci 278:170-178

Coker DJ, Pratchett MS, Munday PL (2012) Influence of coral bleaching, coral mortality and conspecific aggression on movement and distribution of coral-dwelling fish. J Exp Mar Biol Ecol 414-415:62-68

Cole K (2002) Gonad morphology, sexual development, and colony composition in the obligate coral-dwelling damselfish Dascyllus aruanus. Mar Biol 140:151-163

Dugatkin LA, Reeve HK (2000) Game theory and animal behavior. Oxford University Press, New York, NY

Fahrig L (1997) Relative effects of habitat loss and fragmentation on population extinction. J Wildl Manag 61:603-610

Feary DA (2007) The influence of resource specialization on the response of reef fish to coral disturbance. Mar Biol 153:153-161

Forrester GE (1991) Social rank, individual size and group composition as determinants of food consumption by humbug damselfish, Dascyllus aruanus. Anim Behav 42: $701-711$

Frostman P, Sherman PT (2004) Behavioral response to familiar and unfamiliar neighbors in a territorial cichlid, Neolamprologus pulcher. Ichthyol Res 51:283-285

Griffiths SW, Brockmark S, Hojesjo J, Johnsson JI (2004) Coping with divided attention: the advantage of familiarity. Proc R Soc Lond B Biol Sci 271:695-699

Groombridge B (1992) Global biodiversity: status of the Earth's living resources. Chapman \& Hall, New York, NY

> Hastie T, Tibshirani R (1987) Generalized additive models: some applications. J Am Stat Assoc 82:371-386

> Holbrook SJ, Schmitt RJ (2002) Competition for shelter space causes density-dependent predation mortality in damselfishes. Ecology 83:2855-2868 
Jaeger RG (1981) Dear enemy recognition and the costs of aggression between salamanders. Am Nat 117: 962-974

Jones GP, McCormick MI, Srinivasan M, Eagle JV (2004) Coral decline threatens fish biodiversity in marine reserves. Proc Natl Acad Sci USA 101:8251-8253

> Jordan LA, Avolio C, Herbert-Read JE, Krause J, Rubenstein D, Ward A (2010) Group structure in a restricted-entry system is mediated by both resident and joiner preferences. Behav Ecol Sociobiol 64:1099-1106

Katzir G (1981) Aggression by the damselfish Dascyllus aruanus L. towards conspecifics and heterospecifics. Anim Behav 29:835-841

Krause J, Ruxton GD (2002) Living in groups. Oxford University Press, New York, NY

Krebs JR, Davies NB (1997) Behavioral ecology: an evolutionary approach, 4th edn. Blackwell Publishing, Malden, MA

Marshall PA, Baird AH (2000) Coral reefs-bleaching of corals on the GBR differential susceptibilities among taxa. Coral Reefs 19:155-163

Maynard-Smith JM (1982) Evolution and the theory of games. Cambridge University Press, Cambridge

McCormick MI (2009) Behaviourally mediated phenotypic selection in a disturbed coral reef environment. PLoS ONE 4:e7096

Mitchell J (2005) Queue selection and switching by false clown anemonefish, Amphiprion ocellaris. Anim Behav 69:643-652

Munday PL (2001) Fitness consequences of habitat use and competition among coral-dwelling fishes. Oecologia 128: 585-593

Munday PL (2004) Habitat loss, resource specialization, and extinction on coral reefs. Glob Change Biol 10: 1642-1647

Editorial responsibility: Ivan Nagelkerken,

Adelaide, South Australia, Australia
Parker GA (1974) Assessment strategy and the evolution of fighting behaviour. J Theor Biol 47:223-243

Munday PL, Wilson SK (1997) Comparative efficacy of clove oil and other chemicals in anaesthetization of Pomacentrus amboinensis, a coral reef fish. J Fish Biol 51:931-938

Pratchett MS, Munday PL, Wilson SK, Graham NA and others (2008) Effects of climate-induced coral bleaching on coral reef fishes: a review of ecological and economic consequences. Oceanogr Mar Biol Annu Rev 46:251-296

> Shpigel M, Fishelson L (1986) Behavior and physiology of coexistence in two species of Dascyllus (Pomacentridae, Teleostei). Environ Biol Fishes 17:253-265

Sweatman HPA (1983) Influence of conspecifics on choice of settlement sites by larvae of two pomacentrid fishes (Dascyllus aruanus and D. reticulatus) on coral reefs. Mar Biol 75:225-229

Walker SPW, McCormick MI (2009) Sexual selection explains sex-specific growth plasticity and positive allometry for sexual size dimorphism in a reef fish. Proc R Soc Lond B Biol Sci 276:3335-3343

Walker SPW, Thibaut L, McCormick MI (2010) Densitydependent sex ratio adjustment and the Allee effect: a model and a test. Am Nat 176:312-321

Wilson SK, Graham NAJ, Pratchett MS, Jones GP, Polunin NVC (2006) Multiple disturbances and the global degradation of coral reefs: are reef fishes at risk or resilient? Glob Change Biol 12:2220-2234

> Wong MYL, Buston PM, Munday PL, Jones GP (2007) The threat of punishment enforces peaceful cooperation and stabilizes queues in a coral-reef fish. Proc R Soc Lond B Biol Sci 274:1093-1099

> Wong MYL, Munday PL, Buston PM, Jones GP (2008) Monogamy when there is potential for polygyny: tests of multiple hypotheses in a group-living fish. Behav Ecol 19:353-361

Submitted: November 28, 2012; Accepted: July 25, 2013 Proofs received from author(s): November 13, 2013 